Corrigendum

\title{
Corrigendum to "Implementation of tidal turbines in MIKE 3 and Delft3D models of Pentland Firth \& Orkney waters" [Ocean Coast. Manag. 147 (2017) 21-36]
}

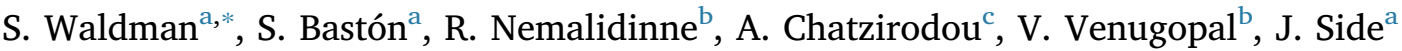

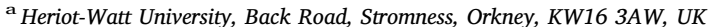 \\ ${ }^{\mathrm{b}}$ Institute for Energy Systems, School of Engineering, University of Edinburgh, Edinburgh, EH9 3JL, UK \\ ${ }^{\mathrm{c}}$ Energy \& Environment Group, Zienkiewicz Centre for Computational Engineering, College of Engineering, Swansea University, Singleton Park, Swansea, SA2 8PP, UK
}

The authors regret that a software error caused incorrect predictions for the effects of tidal turbines in Delft3D. The predictions without turbines are unaffected, as are those from the MIKE 3 model. The overall conclusions of the article remain valid.

Figs. 12-15 as published are incorrect. Replacements for Figs. 12-14 are presented here. Following this correction the differences in the effects of energy extraction between the two models are much smaller. As

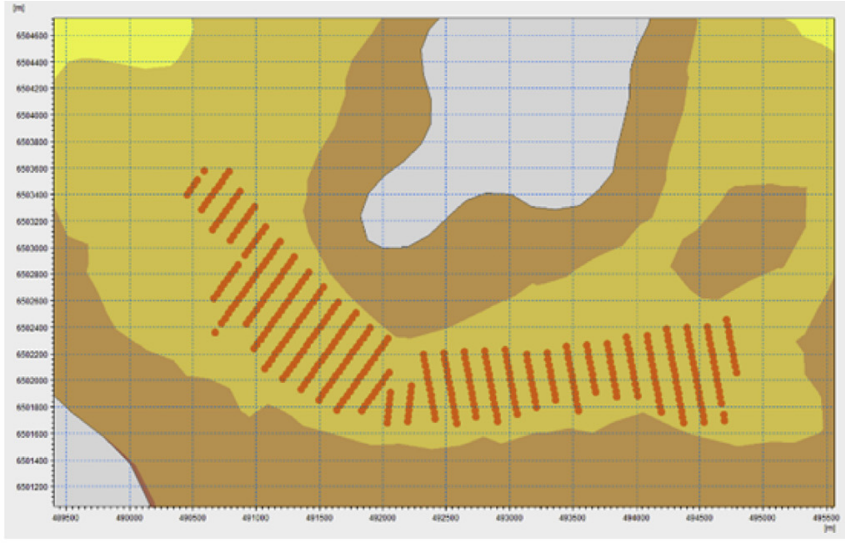

(a) a result the discussion of these differences in Section 6 should be disregarded, and Fig. 15 is no longer required.

The authors would like to apologise for any inconvenience caused. The version of the code for adding turbines to Delft3D that is publicly available has been corrected, and anybody using this for their own work is urged to download the latest version.

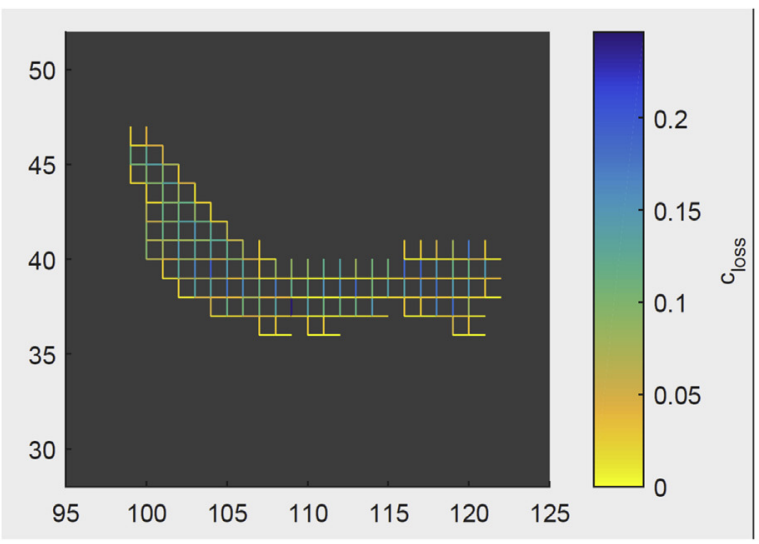

(b)

Fig. 12: (a) 400 turbines in the Inner Sound, viewed through the MIKE Zero GUI; (b) The same 400 turbines represented as porous plates for Delft3D. Higher values of the $c_{\text {loss }}$ parameter, shown by bluer colours, indicate plates with higher drag.

DOI of original article: https://doi.org/10.1016/j.ocecoaman.2017.04.015

* Corresponding author.

E-mail address: s.waldman@hw.ac.uk (S. Waldman). 


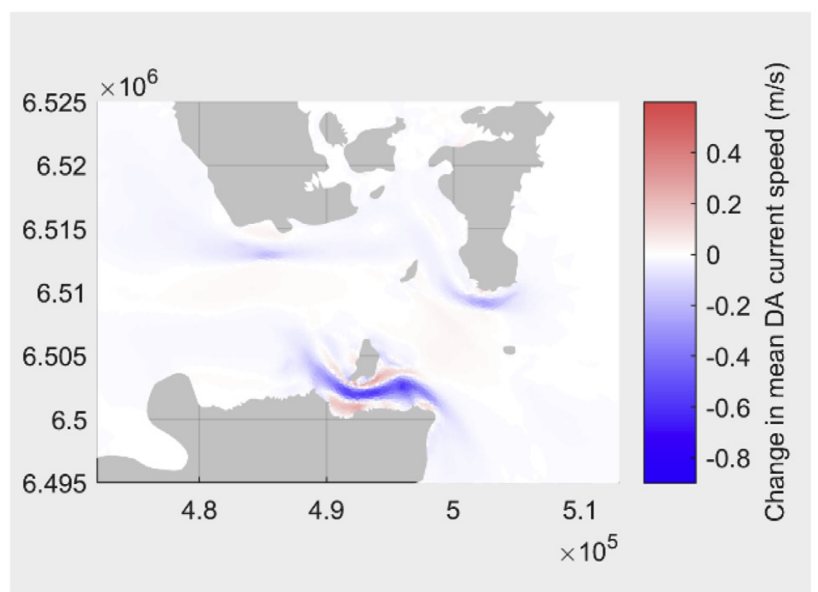

(a) Depth-averaged current speed in MIKE

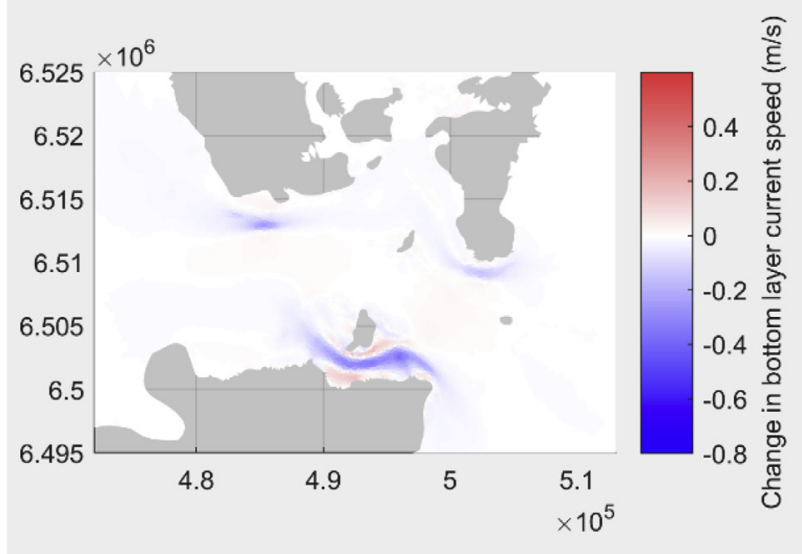

(c) Bottom layer current speed in MIKE

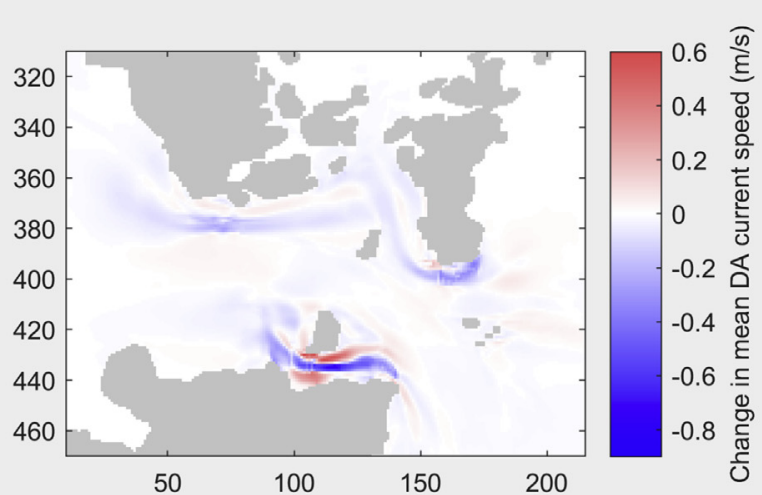

(b) Depth-averaged current speed in Delft3D

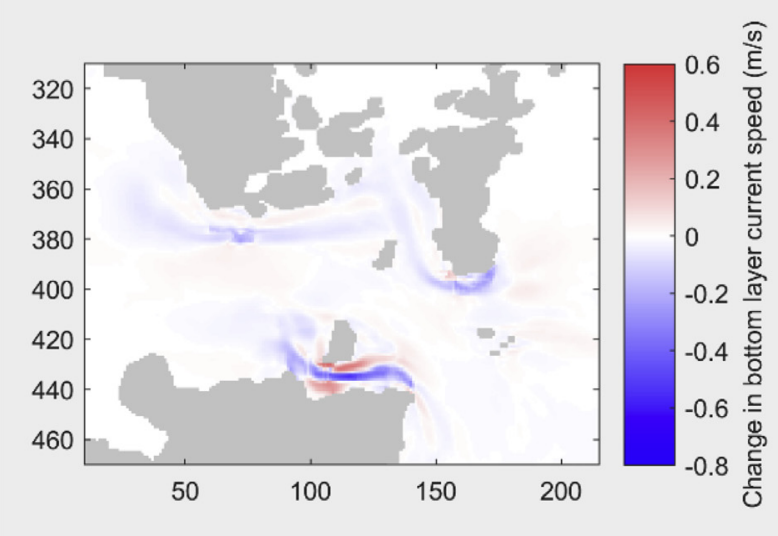

(d) Bottom layer current speed in Delft3D

Fig. 13: Changes in mean current speeds over 28 days as a result of adding turbines.

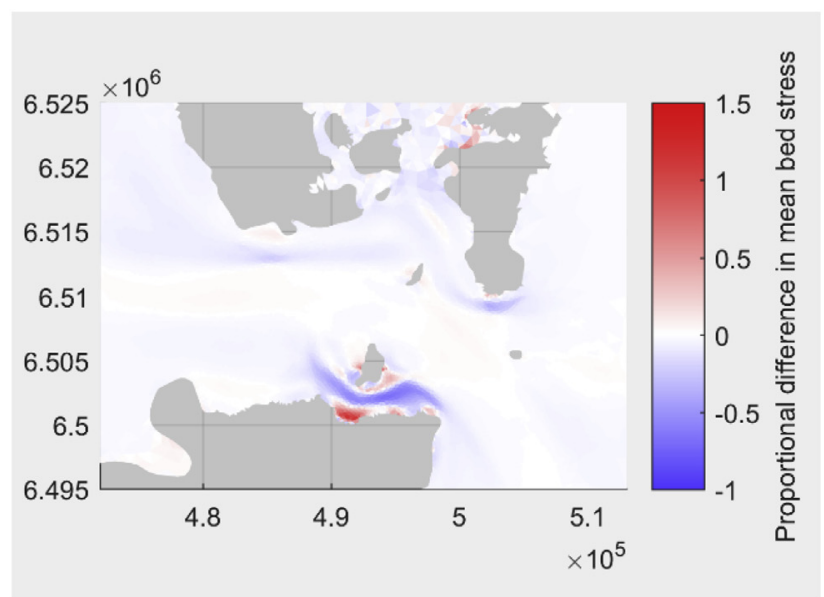

(a) MIKE

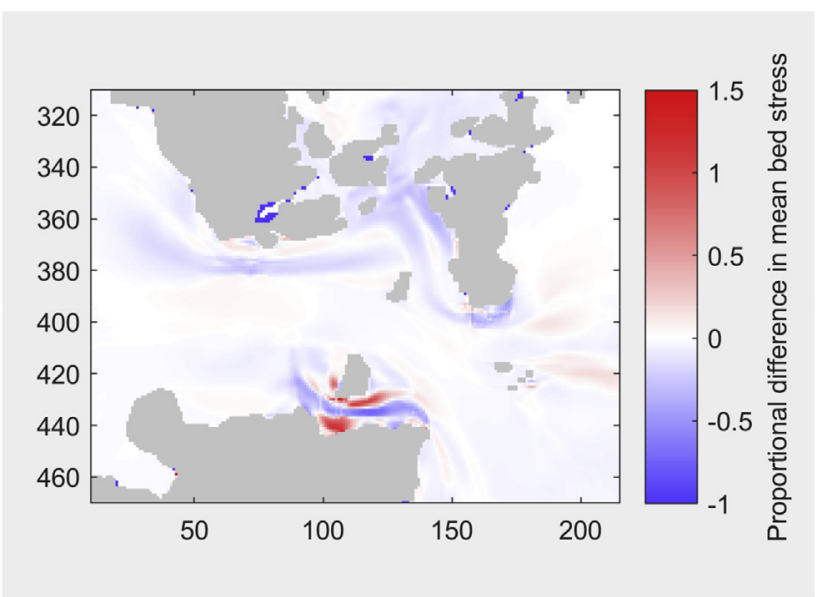

(b) Delft3D

Fig. 14: Change in mean bed stress magnitude over 28 days as a result of adding turbines, expressed as a proportion of the value without turbines. 